\title{
Lifestyle transitions and the developing world: Reflections on the implications for health, well-being and wealth
}

\author{
Ufuoma J ohn Ejughemre \\ Department of Community Medicine, Delta State University Teaching Hospital, Delta State, Nigeria
}

Correspondence: Ufuoma John Ejughemre. Address: Department of Community Medicine, Delta State University Teaching Hospital, Delta State, Nigeria. E-mail: ufuoma.ejughemre@delsuth.com.ng

Received: August 25, 2013

DOI : $10.5430 /$ jha.v3n2p70
Accepted: November 26, 2013

URL: http://dx.doi.org/10.5430/jha.v3n2p70

\section{Abstract}

Context: The past few decades witnessed significant economic growth in many developing countries of the world. These economic changes towards increasing gross domestic product (GDP) brought with it several other transitions in these countries: demographic, epidemiological, technological, and nutritional. These resulted in improving the living standards as well as life expectancy in many of these countries. However, of public health concern is the fact that these transitions paradoxically have their negative consequences on the health, well-being and wealth of the populace in these countries.

Objectives: This review therefore assesses the evidence of the extent to which these changes have affected the living patterns in many developing countries and the epidemiological implications besides others issues on the populace in these countries.

Methods: By using key words, the author involved a broad search of literatures on lifestyle changes, economic growth, nutrition, urbanization, smoking and alcohol, communicable and non-communicable diseases in countries termed low and middle income.

Findings and conclusion: The review identified discernible evidence base about the implications of these changes on health, well-being and wealth of these nations. Accordingly, as lifestyle transitions now come to bear, it thus necessitates an all inclusive approach that will include proactive and pre-emptive interventions as well as consistent participation from governments, multilateral institutions, research-funding agencies, donors, and other players in health systems. This is because it will provide the global community with great opportunities in uniting high, middle, and low-income countries in a common purpose, given the shared interests of globalization and economic burdens worldwide.

\section{Key words}

Developing countries, Globalization, Lifestyles, Economic growth, Health

\section{I ntroduction}

The past few decades witnessed significant economic developments in many developing countries of the world ${ }^{[1]}$. These economic transitions towards increasing gross development product (GDP) brought with it several other transitions: demographic (younger to older population distribution and urbanization), epidemiological (infectious diseases to non- 
communicable diseases); technological (from low to high mechanization); and nutritional (local diets to highly processed energy-dense foods ${ }^{[2-7]}$. Findings from the World Bank reveals that by the turn of 2010 most developing economies had average growth rates of between $5.3 \%$ to $6.5 \%$, with projections of up to $7 \%{ }^{[8]}$. Besides, there have being increased life expectancy at birth in these countries following the Alma Ata declaration on primary health care in $1978^{[9,10]}$. Evidence from the United Nations population division reveals that life expectancy at birth has increased globally particularly in developing countries in the past fifty years ${ }^{[11]}$. It has it that while women and men who were born in these countries at the beginning of the 1950s could live an average of at least 46.6 years, those born between 2005 and 2010 may reach an age of 67.6 years. In fact, these trends now reveal that populations in developing countries have very clearly seen their life expectancy grow by over 20 years, from 41 years in the 1950 s to over 65.6 years ${ }^{[10]}$. This increased life span followed the industrialization, urbanization and economic growth in many of these countries in the past few decades ${ }^{[11,12]}$.

Although these transitions do come to bear, it has not all been economic boom for these countries hitherto. However, this doesn't call for a diminution of the "evolutionary" trends in these countries in the past decades. The paradigm of globalization which started in the 1980s, intensified in the 1990s with the removal of barriers to international trade, foreign direct investments led to unprecedented growths in many of these countries ${ }^{[13]}$. Evidence reveals that there have being remarkable changes as seen in China were there was an unprecedented $8.3 \%$ growth in the $1990 \mathrm{~s}{ }^{[14]}$. Other revelations show that between 1950 to the early 2000s, many countries moved from low income to upper and lower middle income countries ${ }^{[15]}$. Equally, there have being positive growth rates in human developmental indices (HDI) and GDP per capita in India, Indonesia, Malaysia, Latin America and South Africa amongst others ${ }^{[16]}$. These, in no doubt have had its toll on the living standards, with significant changes on the overall life styles of populations in these countries. Nevertheless the global "economic crunch" of the late 2000s caused a dip in growth for many developing countries ${ }^{[17]}$. Notwithstanding, the impact of this crisis varied widely across these countries, with countries in Latin America avoiding big collapses and the region's efforts to reduce macroeconomic and financial vulnerabilities after previous crises has being paying off ${ }^{[17]}$. In fact, there have been some signs of a recovery since the second quarter of 2009 in many developing countries from sub-Saharan Africa to South and South East Asia and the Pacific Islands ${ }^{[18]}$.

Accordingly, the obvious has being the rise in the use of technological tools and scientific research to inform policy in many of these countries ${ }^{[19,20]}$. These have led to advances such as in the area of nutrition and agriculture, housing, urbanization, health care delivery, amongst others ${ }^{[20]}$. This situation reflects in health systems, with findings showing increase in the coverage of low-cost lifesaving public health programmes and the spread of knowledge about health, nutrition, and hygiene among households ${ }^{[13]}$. It could be said that the health gains in China, Costa Rica, the East Asian "tiger economies" and Viet Nam can be attributed in part to their growing access to global markets and technology ${ }^{[13]}$. Nevertheless, there is the rising occurrence of non-communicable diseases alongside communicable diseases in epidemic proportions besides others challenges in these countries. These therefore pose a big challenge to achieving the health targets of the millennium development goals. Consequently, like climate change, the relentless spread in life style transitions should be considered as a critical issue offering an opportunity for global health policy makers to join forces in addressing a major challenge that threatens health and economies alike. This review therefore assess the evidence of the extent to which economic growth, demographic changes, inter alia; have affected the living patterns and the implications of these on populations in these countries.

\section{Methods for review}

As literature reviews are summaries of research evidence that address research questions by using explicit methods to identify, select, critically appraise relevant research studies and analyses data from the studies that are included for the review, the author made this study as inclusive as possible. 


\subsection{Search methods}

By using key words, the author involved a broad search of literatures on lifestyle changes, economic growth, nutrition, urbanization, smoking and alcohol, communicable and non-communicable diseases in countries termed low and middle income. Via broad criteria online search engines and databases including Pubmed, Medline, Embase and Google Scholar were searched, websites and online resources of international organizations as well as hand searches of bibliographic records. However, the author did not contact experts or universities. Original searches were conducted initially between February-April, 2013 and then July to Mid-October, 2013 for documents that were included for the review.

\subsection{Selection criteria}

To generate evidence for the review, studies between 1990-2013 were considered and findings included were from literature reviews, expert commentaries, cross sectional studies, panel discussions as well as grey literatures that reported an objective measure of at least one of the following outcomes: economic growth, nutrition, urbanization, environmental degradation, smoking and alcohol, communicable and non-communicable diseases, as well as the health outcomes in these countries.

\subsection{Data collection, analysis and results}

The findings generated from all included studies formed the themes used to critically analyze lifestyle changes and the implications in these countries. There was no detailed data synthesis and quality assessment as the study is not a systematic review. Three main issues emerged from included studies and these were: (i) Nutritional considerations, (ii) Urbanization and the built environment, (iii) Smoking and alcohol consumption. The review identified discernible evidence base about the implications of these changes on health, well-being and wealth of these nations, while suggesting an all inclusive approach that will include proactive, pre-emptive interventions and consistent participation from governments, multilateral institutions, research-funding agencies, donors, and other players in health systems.

\section{Critical considerations}

As economic growth, urbanization etc are important to bring about development and a reduction in poverty; however, higher levels of GDP does not always translate into greater levels of well-being for citizens ${ }^{[7]}$. Of concern is that these transitions now tally with epidemiological trends that are referred to as the "Double Burden of Diseases": where there is the occurrence of communicable diseases and non-communicable diseases in epidemic proportions in these countries ${ }^{[21]}$. Regrettably, this leads to loss in productivity of the populace, effects on national income and strain on health care systems. Interestingly, the threat of the consequences of these transitions has led some of these countries to find solutions at the levels of policy and health care delivery ${ }^{[22]}$. On the contrary, many of these countries particularly those in sub-Saharan Africa and parts of south Asia still face the problems of inadequate resources, poorly constructed health systems which in many instances are characterised by general lack of expertise to address the rising burden posed by the epidemiologic transitions ${ }^{[22]}$. Accordingly, it is important to critically reflect on issues such as nutritional patterns, urbanization and the built environment, as well as tobacco smoking and alcohol consumption as these cut across existing life style paradigms in these countries and contribute significantly to the health of populations.

\subsection{Nutritional considerations}

Currently the world is facing an energy crisis, a "food crisis", financial crisis and a climate that has begun to change in ominous ways. Notwithstanding, the recent past decades brought about transitions in life styles across many developing countries. These transitions are inextricably linked to the economic and socio-demographic changes as well as globalization prior to the global economic "meltdown" ${ }^{[23,24]}$. Many developing countries now leverage on the global partnership for development, for economic growth and co-operate development. Amongst the many was the signed bilateral trade agreement (BTA) that allows for free flow of trade among the Pacific Islands countries and their industrialized neighbours of Australia, New Zealand as well as the United States ${ }^{[25]}$. Of interest is that it created a channel 
of flow for more processed, affordable and effectively marketable foods within the Pacific Islands countries. These can largely explain the obvious nutritional shifts. The situation now reveals documentations of marked shifts in the structure of the food systems in many of these countries, which now produce more processed, affordable and effectively marketable food than ever before ${ }^{[26-28]}$. Local and traditional diets are rapidly giving way to more "convenient" meals such as pastries, fried foods, refined alcoholic and non-alcoholic beverages ${ }^{[25]}$. Evidence have shown an accelerated change in the nutritional patterns in many societies in developing countries such as in Brazil, Indonesia, India, Malawi, Nigeria and even among the Polynesians in the Pacific ${ }^{[26]}$. Populations in these countries now converge on diets high in saturated fat, refined sugar and processed foods that are low in fibre and natural nutrients ${ }^{[27-30]}$.

Although, the recent "economic crunch" of the late 2000s caused a marked increase in food prices in developing countries, where the average household now spend as much as $80 \%$ of its disposable income to buy food ${ }^{[31]}$ on the contrary it further strengthens the reasons for higher consumption of processed foods, full of fat and sugar and low in essential nutrients which have now become the staple foods, unlike healthy foods which are almost always the most expensive, like fruits and vegetables and sources of high quality protein. Equally is the fact that many citizens in countries such as Brazil, China and South Africa spend considerable sums of money on "unhealthy" foods of which there is now increased access to ${ }^{[32]}$. Anecdotes reveals that, besides the increased income per capita, the other reasons for these new paradigms-dietary shifts-includes convenience and leisure. The drivers of these dietary trends are in the food system: the rising supply of palatable, energy-dense foods; with improved distributing systems to make food much more accessible and more convenient ${ }^{[33]}$. More so, is the fact that the trend is compounded by the presence of many transnational food companies which have launched aggressive marketing campaigns to penetrate consumer bases in these nations, precisely because of the favourable socio-economic trends in the past few decades ${ }^{[32,34]}$. The situation is responsible for the increased calorie intake by populations in these countries ${ }^{[35]}$. Facts have shown that the average calorie intake in countries in parts of Asia, Latin America and some pacific Island countries is at par with what is obtainable in Western Europe and North America (i.e between $3000 \mathrm{kcal} /$ day-3600 kcal/day) ${ }^{[35]}$. For instance, a study in urban areas of China showed that in a recipe containing pork and egg there was a noticeable increase in the amount of pork and egg in the dish within three years ${ }^{[35]}$. The same also revealed that the amount of pork increased by 9.7 grams and the amount of egg increased by two grams within the same period. As it were, many settings in Asia, Middle East, the Pacific, North Africa and Urban areas of sub-Saharan Africa are now experiencing dietary-shifts which is fuelling the rise in overweight and non-communicable disease epidemics ${ }^{[26-28]}$.

The epidemiologic consequence of these shows the rising prevalence of overweight with elevated incidence of degenerative diseases ${ }^{[36,37]}$. These findings have also tallied with reports of increasing incidence of childhood obesity in some of these countries ${ }^{[38]}$ and this can't be mutually exclusive from the rise in consumption of processed foods. The trends in childhood obesity is of concern to health professionals because childhood obesity is the likely precursor to a rise in cases of some childhood disease such as paediatric metabolic syndrome and the consequences of these on the health systems and health care delivery cannot be underestimated ${ }^{[38]}$. Additionally, in Brazil facts from repeated cross-sectional surveys of body mass index (BMI) reveals that obesity rates increased rapidly amongst middle- aged women of all social strata ${ }^{[39,40]}$. By 2004, the disability attributed to overweight and obesity was calculated at more than 36 million disability-adjusted life years globally with this accounting for up to $6 \%$ of total health care costs in many of these developing countries ${ }^{[41,42]}$. Diseases like diabetes, coronary heart disease and many cancers such as colorectal cancers are rising in these countries ${ }^{[41,43]}$. Evidence from a meta-analysis showed increasing trends in the prevalence of hypertension and its complications in India between the late $1950 \mathrm{~s}$ and $1990 \mathrm{~s}{ }^{[44]}$. More so, the prevalence of hypertension in Nigeria - a sub-Saharan African country - increased from $8.6 \%$ in the late 1970 s to as high as $22.5 \%$ by $2011^{[42]}$. While, the global prevalence of diabetes among adults (aged 20 years- 79 years) is expected to increase to $7.7 \%$ by 2030 , there will be a $69 \%$ increase in numbers of adults with diabetes in developing countries ${ }^{[43]}$. These issues do call for a deep reflection on the implications for many in these countries; the sad fact is the economic implications it will have, most notably of which is the loss in productivity of the populace, effects on national income and the economy as well as the strain on health care systems. 


\subsection{Urbanization and the built environment}

The effect of these changes has seen large scale urbanization and socio-demographic changes in these countries ${ }^{[15]}$. There have been wide scale improvements in housing, social service sectors such as roads, and growth of cities and megacities ${ }^{[15]}$. Nevertheless, as urbanization is needful for improved living standards; paradoxically, it "marginalizes" the health of population in these countries. As it were, the socio-demographic changes witnessed in many developing countries have culminated in the problems of environmental degradation and man-made disasters ${ }^{[15]}$. Projections have it that by 2030, Africa for instance will be severely affected from issues relating to climate change, water shortage, etc ${ }^{[45]}$. It is expected by then, that the greatest stress from lack of water will affect between 75 million and 250 million Africans ${ }^{[46]}$. This will increase the challenges of emerging and re-emerging diseases; rising prevalence of the neglected tropical diseases such as schistosomiasis and guinea worm infection, epidemics of dysentery, diarrhea and cholera. The roll back malaria programme may be jeopardized as water scarcity will cause many to store water within household which amplifies the risk of malaria and dengue fever spread by mosquitoes ${ }^{[47]}$. There will also be the challenges of food insecurity with the impacts of malnutrition. Needless to say is the impact poor urbanization and environmental degradation will have outside the African Continent. Sadly, developing countries face greater urbanization challenges than developed countries. While developed countries urbanized at a much leisure pace the same can't be said for many developing countries. Notably, the United States was 70\% urbanized in 1960 s and $75 \%$ in $1990^{[48]}$. This pace is in contrast with that in many developing countries. The Republic of Korea for example was $40 \%$ urbanized in 1970 and by 1990 it was $78 \%{ }^{[49]}$. What took the United States 90 years to accomplish took Korea 20 years and Brazil 30 years. It is possible that this rapid urbanization combined with the relatively increased GDP has not allowed for enough reasonable form of urbanization and the needed quality of life by most of the populace in these countries. The import being that for rapidly urbanizing developing countries, the needed cultural change to adapt rural life style to urban one has become a "crash course". Besides, nearly fifty percent of the populations in developing countries now live in areas classified as urban ${ }^{[50]}$.

Equally, the other critical challenge is that these changes now contribute to what is referred to as the "built environment" ${ }^{\text {[51] }}$. This constitutes such an environment within the home or workplace that promotes physical inactivity, weight gain, and is not conducive for weight loss ${ }^{[51]}$. In fact, it provides the "template" for increased consumption of energy, resources, transport, land and industrial growth in the face of the spread of the sedentary automobile-and-television culture $^{[52]}$. The observable impact of the built environment is largely due to modernization of social infrastructures and industrialization in these countries over the years ${ }^{[53,54]}$. The built environment complicates efforts aimed at addressing the existing health burden in these countries as seen in its negative effect in increasing physical inactivity by promoting a sedentary culture among human populations in many societies in developing countries and the attendant increased prevalence of overweight with the sequealae of noncommunicable diseases ${ }^{[49,55]}$. Evidence show that overweight is now an issue in many of these countries as it does correlate positively with urbanization ${ }^{[19,62,67]}$. Revelations from a study showed that two indicators (GDP and urbanization) were positively associated with the prevalence of overweight ${ }^{[56]}$. By collecting and analyzing data on BMI of women aged 29 years-49 years from 36 developing countries spread across Asia, Latin America and sub-Saharan Africa, the study showed that overweight exceeded underweight in well over half of the countries: the median ratio of overweight to underweight was 5.8 in urban and 2.1 in rural areas. These epidemiological transitions now come to bear. The import is the rising incidence of the epidemiological sequealae: hypertension, cardiovascular diseases such as stroke, and cancers such as colorectal cancers ${ }^{[43]}$. This has implications for attaining the health related millennium development goals in these countries.

\subsection{Smoking and alcohol consumption}

Interestingly, these are inextricably linked and yet some of the most controversial life style issues bothering scientists and health policy makers alike. Tobacco smoking has been linked with a number of related cancers of which include cancers of the lungs, oropharyngeal cancers and some gastrointestinal cancers ${ }^{[57]}$. Smoking, is associated with physical inactivity, greater consumption of alcohol and lower consumption of fruits, vegetables and dietary fibres ${ }^{[58]}$. Likewise, tobacco smokers are some of the major consumers of alcoholic beverages in various forms ${ }^{[59,60]}$. Concurrent use of these 
substances poses a significant public health threat as tobacco smoking and alcohol consumption have been shown to be synergistic in creating many adverse health conditions ${ }^{[61,62]}$. What is important to policy makers is the rising trend in tobacco smoking in developing countries ${ }^{[62,63]}$.

While there may be assertions that smoking and alcohol consumption do not have direct bearing with economic growth, chiefly is the fact that, of the 1.22 billion smokers globally, one billion of them live in developing or transitional economies ${ }^{[64]}$. In fact, while the rate of tobacco smoking has declined in the developed world, in developing countries tobacco consumption has being on the rise and by 2002 reached $3.4 \%$ increase per year ${ }^{[63]}$. The sad fact is that projections have it that by the year 2025, 1.9 billion people will be smokers with most of them living in developing countries ${ }^{[64]}$. Sadly, anecdotes reveal that social activities in developing countries are now a "haven" for smoking and consumption of alcoholic beverages at rapacious levels which prior to now may have been considered as an anathema.

Additionally, the public health challenges of consuming alcoholic beverages come to bear. While there are measurements for tobacco smoking, it is however difficult to ascertain those for alcohol consumption ${ }^{[65]}$. Estimates of per capita alcohol consumption may be derived from production, trade and/or sales figures. However, these figures are rarely available even in developed countries much less developing countries. For instance, detailed studies which estimated the size of unregistered consumption in East Africa yielded estimates of the total consumption of alcohol where that for Tanzania and for Kenya were about $90 \%$ and $85 \%$ respectively of the proportion of total alcohol produced and these were anecdotal. More so, many of these countries such as in those in Asia (with the exception of Japan), Latin America and Africa, recorded per capita consumption increase between 1961 to the late $1990 \mathrm{~s}{ }^{[65]}$. It is believed that the reasons behind this trend is both political and economic. Facts reveal subtle political and economic mechanics favouring the growth of the alcohol, tobacco and allied industries in many developing countries at the expense of health ${ }^{[66,67]}$. Systematic approaches by local firms to remain attractive to public policy makers include; portraying themselves as a mainstay in the economy considering that they provide jobs and revenue through taxation ${ }^{[67]}$. More so, it appears that policy actions in many of these countries have paved the way for increased access to and consumption of these products in the recent past, as the revenue generated from taxation policies on their sales have kept these industries afloat over the decades ${ }^{[68]}$. However this argument, particularly by the tobacco industry has been rebuffed by global international institutions such as the World Bank, as there are calls for a rapt attention on these amidst the so-called robust economic inputs ${ }^{[69]}$. These therefore necessitate reflections on the impacts of these on health, health systems and paradoxically the economy.

\section{Further reflections}

Although, communicable diseases still continue to be important causes of death in many of these countries, the global burden of disease is now shifting from communicable diseases to noncommunicable diseases particularly diseases arising from lifestyle transitions, with chronic conditions such as cardiovascular diseases: hypertension and stroke as well as cancers being the chief cause of disability and death (or disease burden) with epidemic proportions occurring in these countries ${ }^{[70,71]}$. This shifting health trends indicate that leading infectious diseases - diarrhea, HIV/AIDS, tuberculosis, and malaria - will become less important causes of disease burden in these countries over the next 20 years that is by $2030{ }^{[71]}$. Importantly, as globalization and the proliferation of life style changes continue, it is becoming increasingly common to observe in these countries the perennial battle with century old issues of communicable diseases and noncommunicable diseases. Issues of environmental degradation and man-made disasters which results in water scarcity (economic and physical) in regions like sub-Saharan Africa should be critically considered. While these countries continue to develop besides life style changes, paradoxically, the impacts of this on health, agriculture, education, etc. do come to bear.

Additionally, is the projection for costs of treatment and the deleterious effects on individual productivity as diseases of life style will take catastrophic tolls on the economic life of individuals, families, and societies in many of these countries. It follows that, the 2009 World Economic Forum's report proposes that diseases of life style changes are among the most 
severe threats to global economic development, more likely to be realized and potentially more "detrimental" than fiscal crises, natural disasters, or pandemic influenzas ${ }^{[72]}$. Its projections show that in the next 10 years- 15 years, China and India alone will lose approximately $\$ 558$ billion and $\$ 237$ billion respectively in national income as a result of largely preventable diseases-cardiovascular diseases, diabetes and cancers ${ }^{[72]}$. For 5.6 billion people in countries of low and middle income, more than half of all health spending is covered by direct payments ${ }^{[73]}$. This health financing system is very inefficient and necessitates policy reforms that will reduce the regressive burden of out-of pocket expenditure and at the same time overdependence on government budgetary allocation to health. Although, the threat of the consequences of these transitions has led some of these countries to find solutions at the levels of policy and health care delivery ${ }^{[71]}$, however; many of these countries particularly those in sub-Saharan Africa and south Asia still face the problems of inadequate resources, poorly constructed health systems which in many instances are characterized by general lack of expertise to address the rising burden posed by the epidemiologic transitions ${ }^{[72]}$. Ultimately, these challenges now offer opportunities for regional and global integration and cooperation.

\section{Conclusion}

As life style transitions now come to bear, it thus necessitates an all inclusive approach that will include proactive and pre-emptive interventions as well as consistent participation from governments, multilateral institutions, research-funding agencies, donors, and other players in health systems ${ }^{[71]}$. There is the need to increase the sense of urgency regarding the implications of these transitions that are "communicated" by means of economic, social and demographic changes, lest they insidiously undermine the health, wellbeing and wealth of these nations. This is because it will provide the global community with great opportunities in uniting high, middle, and low-income countries in a common purpose, given the shared interests of globalization and economic burdens worldwide.

\section{Competing interests}

This paper clearly expresses the views of the author as there are no competing interests. For enquires on the views of this document please contact the author.

\section{References}

[1] Perspectives on global development. Economy: Developing countries set to account for nearly $60 \%$ of world GDP by 2030 , according to new estimates. Available from:

http://www.oecd.org/dev/pgd/economydevelopingcountriessettoaccountfornearly60ofworldgdpby2030accordingtonewestimates. htm. Accessed April 24, 2013.

[2] Mason A. Demographic Transition And Demographic Dividends in Developed And Developing Countries, 2005. Available from: http://www.un.org/esa/population/meetings/Proceedings_EGM_Mex_2005/mason.pdf. Accessed 1st July, 2013.

[3] Mason A, Canning, D. Cumulative causality, economic growth, and the demographic transition. In Population Matters: Demographic Change, Economic Growth, and Poverty in the Developing World, Oxford: Oxford University Press, 2001; 165-200.

[4] World Health Organization (WHO) World Health Statistics. WHOSIS (WHO Statistical Information System). 2007. Available from: http://www.who.int/whosis/whostat2007/ en/index.html. Accessed 12th April, 2013.

[5] Arthur S, Sheffrin SM. Economics: Principles in Action. Upper Saddle River, New Jersey 07458: Pearson Prentice Hall. $2003 ; 471$.

[6] Composition of macro geographical (continental) regions, geographical sub-regions, and selected economic and other groupings (footnote C). United Nations Statistics Division. revised 17 October 2008.

[7] Swinburn, B., Sacks, G., Hall, K., McPherson K., Finegood, D., Moodie, M., et al. The global obesity pandemic: shaped by global drivers and local environments. Series. Lancet. 2011; 378, pp. 804-14. http://dx.doi.org/10.1016/S0140-6736(11)60813-1

[8] The World Bank, Data and Statistics. Developing Countries Are Driving Global Growth, but Risks Remain. Available from: http://econ.worldbank.org/WBSITE/EXTERNAL/EXTDEC/0, contentMDK:22806935 pagePK:64165401 piPK:64165026 the SitePK:469372,00.html. Accessed 1st July, 2013.

[9] Rohde J, Cousens S, Chopra M, Tangcharoensathien V, Black R, Bhutta ZA, et al. 30 years after Alma-Ata: has primary health care worked in countries? Lancet. 2008 13; 372(9642): 950-61. 
[10] Inequality watch. The Evolution of Life Expectancy in the World 2010. Available from: http://www.inequalitywatch.eu/spip.php?article106. Accessed 29th June, 2013.

[11] Bożyk P. Newly Industrialized Countries. Globalization and the Transformation of Foreign Economic Policy. Ashgate Publishing, 2006.

[12] David W. Manufacturing industries (chapter 19), World development (chapter 22). Geography, An Integrated Approach. Nelson Thornes Ltd. 2000; 563, 576-579, 633, and 640.

[13] Cornia G.A. Globalization and health: results and options. Bulletin of the World Health Organization. $2001 ; 79$ (9): $834-837$. PMid: 11584731.

[14] Economic Growth Rates. A World Bank Report. 2010; 23-24. Available from: http://www.worldbank.org/depweb/beyond/beyondco/beg_04.pdf. Accessed 1st July, 2013.

[15] United Nations. World Economic and Social Survey 2009: Promoting Development, Saving the Planet. United Nations Department of Economic and Social Affairs. 2010; 3-5.

[16] Munoz P, Darkey E, Oleson K, Pearson L. Accounting for the Inclusive wealth of nations: empirical evidence. Inclusive Wealth Report. 2012; 34.

[17] Berkmen,P., Gelos G., Rennhack, R, Walsh J.P. The Global Financial Crisis: Explaining Cross-Country Differences in the Output Impact. International Monetary Fund Working Paper, 2009.

[18] Willen te Velde, et al. The global financial crisis and developing countries phase 2 synthesis. Working Paper 316 Results of ODI research presented in preliminary form for discussion and critical comment. 2010.

[19] London L. What is a human rights-based approach to health and does it matter? Health and Human Rights. 2009; 10: 1.

[20] Food and Agricultural Organisation. The State of Food and Agriculture 2007, Paying Farmers for Environmental Services (Rome: FAO, 2007); Oxfam International, Causing Hunger: An Overview of the Food Crisis in Africa, Oxfam Briefing Paper 91 (London: 2006).

[21] World Health Organization (WHO). 2004. Bulletin of the World Health Organization: Developing countries face double burden of disease. Available from: http://www.ncbi.nlm.nih.gov/pmc/articles/PMC2622909/pdf/15500291.pdf. Accessed 17 th July 2012.

[22] Daar AS, Singer PA, Persad DL, et al. Grand challenges in chronic non-communicable diseases. Nature 2007; 450: 494-6. PMid: 18033288. http://dx.doi.org/10.1038/450494a

[23] Popkin B. The Nutrition Transition and Obesity in the Developing World. American Society of Nutrition. The Journal of nutrition. 2004; 131(3).

[24] Popkin, Barry. Stages of the Nutrition Transition: Dynamic Global Shifts Appear to be Accelerating. 2002. Available from: http://www.sne.org/conference/documents/BarryPopkin-NutritionTransition.pdf. Accessed April 21st, 2013.

[25] Fiji Government online portal (2011). fiji.gov.fj, Available from: http://www.fiji.gov.fj/index.php?option=com_content\&view=article\&id=646\&Itemid=197. Accessed 19th July, 2012.

[26] Kim, S., Moon, S., Popkin, B. The nutrition transition in South Korea. American Journal of Clinical Nutrition. 2000 ; $71: 44-53$. PMid: 10617945.

[27] Monteiro, C., Mondini, L., Medeiros de Souza, A., Popkin, B. The nutrition transition in Brazil. European Journal of Clinical Nutrition. 1995; 49, pp: 105-113. PMid: 7743983.

[28] Popkin, B. M. The nutrition transition in low-income countries: an emerging crisis. Nutrition Review. 1994; 52, pp: $285-298$. PMid: 7984344. http://dx.doi.org/10.1111/j.1753-4887.1994.tb01460.x

[29] Hodge, A.M, Dowse, G.K, Gareeboo, H., Tuomilehto, J., Alberti, K.G., Zimmet, P.Z. Incidence, increasing prevalence, and predictors of change in obesity and fat distribution over 5 years in the rapidly developing population of Mauritius. International Journal of Obesity and Related Metabolic Disorders: Journal of the International Association for the Study of Obesity. 1996; 20(2): 137-146.

[30] Colagiuri, S.C., De Courten, M.P., David W. Dunstan, Dwyer, T. The rising prevalence of diabetes and impaired glucose tolerance: the Australian diabetes, obesity and lifestyle study. Diabetes Care. 2005; $25: 829$.

[31] The state of food insecurity in the world 2004: monitoring progress towards the World Food Summit and Millennium Development Goals. Rome: Food and Agriculture Organization; 2004. Available from: ftp://ftp.fao.org/DOCREP/FAO/007/Y5650E/Y5650E00.PDF. Accessed 27th October, 2013.

[32] Darnton-Hill I, Nishida C, James WP. A life course approach to diet, nutrition and the prevention of chronic diseases. Public Health Nutrition. 2004; 7 (1A): 101-121. PMid: 14972056. http://dx.doi.org/10.1079/PHN2003584

[33] Culter DM, Glaser EL, Sharpiro JM. Why Have Americans become more obese? J Econ Perspect. 2003; 17 : $93-118$. http://dx.doi.org/10.1257/089533003769204371

[34] Wolf AM, Manson JE, Colditz GA. The economic impact of overweight, obesity and weight loss.2002 Ed. Eckel R in Obesity: Mechanisms and clinical management. Lippincott, Williams and Williams. 2003. 
[35] Compendium of food and agriculture indicators, Food and Agricultural Organization (FAO), 2006. Retrieved 18th February, 2009.

[36] Ulijaszek, S. J. Nutrition, Infection and Child Growth in Papua New Guinea. Coll. Antropol. 2000; 24(2): 423-429. PMid: 11216411.

[37] Ulijaszek, S. J. Annals of Human Biology. 2001; 28 (4): 363-411. PMid: 11459234. http://dx.doi.org/10.1080/03014460152438955

[38] Roya, K. Childhood Overweight, Obesity, and Metabolic Syndrome in Developing Countries. 2007.

[39] International Association for the study of Obesity, International Obesity Task Force. Global Childhood overweight.

[40] International Association for the study of Obesity, International Obesity Task Force. Global Obesity in Adults.

[41] Ezzati, M., Lopez, A., Rodgers, A., Murray, C. Comparative quantification of health risks: global and regional burden of disease attributable to selected major risk factors. Geneva: World Health Organization. 2004.

[42] WHO. Prevention and control of noncommunicable diseases: implementation of the global strategy. Sixty-first World Health Assembly, Resolution WHA61.14. Geneva: World Health Organization. 2007.

[43] Shaw JE, Sicree R.A, Zimmet P.Z. Global estimates of the prevalence of diabetes for 2010 and 2030. Diabetes Research and Clinical Practice. 2010; 87(1): 4-14. PMid: 19896746. http://dx.doi.org/10.1016/j.diabres.2009.10.007

[44] Gupta R. Meta-analysis of prevalence of hypertension in India. Indian Heart Journal. 1997; 49(1): 43-8. PMid: 9130424.

[45] Conference on "Water Scarcity in Africa: Issues and Challenges", 2012. Available from: http://www.gisclimat.fr/manifestation-scientifique/conf $\% \mathrm{C} 3 \% \mathrm{~A} 9$ rence $\% \mathrm{E} 2 \% 80 \% 9 \mathrm{Cwater}$-scarcity-africa-issues-and-challenges $\%$ E2\%80\%9D. Accessed 25th October, 2013.

[46] Water Scarcity: The Importance of Water and Access Available from: http://thewaterproject.org/water_scarcity.php. Accessed 25th October, 2013.

[47] Ten Facts about water scarcity. WHO, 2009. Available from: http://www.who.int/features/factfiles/water/en/. Accessed, 25th October, 2013.

[48] World Bank. Indonesia: Urban Infrastructural Services. World Bank East Asia and Pacific Water infrastructure Division. Washington DC. 1993.

[49] World Cancer Research Fund (WCRF) and American Institute for Cancer Research. Food, nutrition, physical activity, and the prevention of cancer: a global perspective. Washington, DC: American Institute for Cancer Research. 2007.

[50] Henderson V. Urbanization in Developing Countries. The World Bank Research Observer. 2002; 171: 1-2.

[51] Swinburn B., Egger, G., Raza, F. Dissecting Obesogenic Environments: The Development and Application of a Framework for Identifying and Prioritizing Environmental Interventions for Obesity. Preventive Medicine. 1999; 29: 563-570. PMid: 10600438. http://dx.doi.org/10.1006/pmed.1999.0585

[52] Narayan V.K, Mohammed M.D, Ali, K., Koplan, J.P. Global Noncommunicable Diseases - Where Worlds Meet. 2010. N Engl J Med 363: 13. PMid: 20860499. http://dx.doi.org/10.1056/NEJMp1002024

[53] Mendez MA, Popkin BM. Globalization, urbanization and nutritional change in the developing world. Electron J Agric Devel Econ. 2004; 1: 220-41.

[54] The World Bank Research Observer. International Development and Reconstruction Bank. 2002; 17(1); 89-112.

[55] Huxley R., et al. The impact of dietary and lifestyle risk factors on risk of colorectal cancer: A quantitative overview of the epidemiological evidence. 2009; 125(1): 171-180.

[56] Mendez MA, Monteiro CA, Popkin BM. Overweight exceeds underweight among women in most developing countries. American Journal of Clinical Nutrition. 2005; 81: 714-2. PMid: 15755843.

[57] Hardman JG, Limbird LE, Molinoff P.B, et al. Goodman and Gilman's The Pharmacological Basis of Therapeutics. 9th ed. New York: McGraw-Hill, 1995.

[58] Shiffman, S., Balabanis, M. Associations between alcohol and tobacco. In: Fertig, J.B., and Allen, J.P. Alcohol and Tobacco: From Basic Science to Clinical Practice. NIAAA Research Monograph No. 30. NIH Pub. No. 95-3931. Washington, DC: Supt. of Docs., U.S. Govt. Print. Off., 1995; 17-36.

[59] Patten C.A, Martin, JE, Owen N. Can psychiatric and chemical dependency treatment units be smoke free? J Subst Abuse Treat. 1996; 13(2): 107-118. http://dx.doi.org/10.1016/0740-5472(96)00040-2

[60] U.S. Department of Health and Human Services. The Health Consequences of Smoking: Cancer, a Report of the Surgeon General. DHHS (PHS) No. 82-50179. Washington, DC: Supt. of Docs., U.S. Govt. Print. Off., 1982.

[61] Garro A.J, Espina N., Lieber CS. Alcohol and cancer. Alcohol Health Res World. 1992; 16(1): 81-86.

[62] WHO/WPRO-Smoking Statistics. World Health Organization Regional Office for the Western Pacific. 2002.

[63] Centers for Disease Control and Prevention (CDC) (2009). Cigarette smoking among adults and trends in smoking cessation United States, 2008. Morbidity and mortality weekly report. 58 (44): 1227-1232. PMid: 19910909. 
[64] Guindon G, Boisclair E, David E. Past, current and future trends in tobacco use. Washington DC: The International Bank for Reconstruction and Development/The World Bank. 2003; 13-16.

[65] Jernigan D. Alcohol in Developing Societies: A Public Health Approach. World Health Organization. 2002; 10-12.

[66] Otañez MG, Mamudu H, Glantz SA. Global leaf companies control the tobacco market in Malawi. Tob Control 2007; $16: 261-269$. PMid: 17652242. http://dx.doi.org/10.1136/tc.2006.019273

[67] Saloojee Y, Dagli E. Tobacco industry tactics for resisting public policy on health. Bull World Health Organization. 2000; 78(7). PMid: 10994263.

[68] Otanez M.G, Mamudu H.M, Glantz SA. Tobacco Companies use of Developing countries' Economic Reliance on Tobacco to Lobby Against Tobacco Control. Am J of Public Health. 2009; 99(10): 1759-1771. PMid: 19696392. http://dx.doi.org/10.2105/AJPH.2008.146217

[69] Jha P, Chaloupka FJ. Curbing the epidemic: governments and the economics of tobacco control. Washington, DC, The World Bank, 1999.

[70] WHO technical report series 916. Diet, nutrition, and the prevention of excess weight gain and obesity. Report of a joint WHO/ FAO expert consultation. Geneva: WHO. 2003. Available from: http://www.who.int/hpr/NPH/docs/who_fao_expert_report.pdf. Accessed 7th January, 2007.

[71] United Nations (UN) General Assembly Draft Resolution report on Non-Communicable Diseases, 2011.Sixty-sixth session, item 117; 1-13.

[72] Yach D, Hawkes C, Gould CL, Hofman KJ. The global burden of chronic diseases: overcoming impediments to prevention and control. JAMA. 2004; 291: 2616-22. PMid: 15173153. http://dx.doi.org/10.1001/jama.291.21.2616

[73] Waiswa W.P. The impact of user fees on access to health services in low- and middle-income countries: RHL commentary (last revised: 1 May 2012). The WHO Reproductive Health Library; Geneva: World Health Organization. 